niques using $\mathrm{X}$-ray diffraction to determine stone composition and crystallization experiments to study growth. There are several types of calculi each having different major constituents and a different aetiology: juvenile bladder and a few kidney stones (ammonium acid urate and calcium oxalate), adult bladder stones (uric acid), adult kidney and some bladder stones (calcium oxalate and phosphates and, in certain countries, uric acid) (Lonsdale, Sutor \& Wooley, 1968a,b; Sutor \& Wooley, 1969, 1970b). The geographical and historical distributions of these groups are quite different, but there is evidence of a recurrent historical pattern of change in the type and composition of stones as a country becomes technically developed. The emphasis changes from endemic bladder stones in children to kidney stones in adults (Andersen, 1968). The endemic stones found in this country and Europe years ago are common today in poorer parts of developing countries like India and Thailand. With improved standards of living the disease dies out. In the industrialized countries adult kidney stones are the most common type and are on the increase. They consist predominantly of calcium oxalate and/or calcium phosphate and sometimes struvite $\left(\mathrm{MgNH}_{4} \mathrm{PO}_{4},-\right.$ $6 \mathrm{H}_{2} \mathrm{O}$ ) if the urine becomes infected. In parts of Europe and the Middle East, uric acid is also a major constituent (Lonsdale et al. 1968b; Sutor \& Wooley, 1970b). The important constituent of endemic stones, ammonium acid urate, is rarely found in these calculi.

Urinary calculi consist predominantly of crystalline material, and for nucleation and growth to occur, urine must be saturated or supersaturated. As many highly saturated urines never form stones, it is thought that the presence or absence of inhibitors of crystallization (substances which prevent or slow down crystal growth) may explain the difference between stone-formers' and non-stoneformers' urines. Experimental evidence on the ability of different urines to deposit apatite crystals in various mineralizing systems in vitro shows a basic difference between urines from non-stoneformers and recurrent calcium-stone-formers and suggests the presence of an inhibitor of calcification in the urine from non-stone-formers (Howard \& Thomas, 1958; Thomas, 1969). Studies on the growth rate of calcium oxalate deposits in different urines gradually saturated with calcium and oxalate ions indicate the presence of a powerful inhibitor of calcium oxalate crystal growth in urines from nonstone-formers, which is absent or present in smaller amounts in urines from calcium-stone-formers (D. J. Sutor, unpublished work). Urines lacking this inhibitor soon form crystalline deposits if any factor increases the $\mathrm{Ca}^{2+}$ or oxalate ion concentration whereas urines containing the inhibitor are not so susceptible to such fluctustions.

The principle of inhibition of crystal growth by the presence of foreign compounds or ions in the crystallizing medium suggests a possible method of treatment of urinary stone disease. Experiments in vitro have shown that the rate of growth of calcium oxalate deposits can be retarded by many substances in particular those that form soluble stable complexes with the $\mathrm{Ca}^{2+}$ or oxalate ion and those that are absorbed on to crystal faces and so prevent further growth (Sutor, 1969; Sutor \& Wooley, 1970a). Tests on urines collected before and after administration of one of these compounds (Methylene Blue) to habitual formers of calcium oxalate stones showed the dye usually prevented crystalluria, slowed down nucleation in the urine and substantially decreased the rate at which crystalline deposits already present grew (Sutor, 1970).

Andersen, D. A. (1968). Hosp. Med. 2, 1024.

Howard, J. E. \& Thomas, W. C., jun. (1958). Trans. Am. clin. clim. Ass. 70, 94.

Lonsdale, K., Sutor, D. J. \& Wooley, S. E. (1968a). Br. J. Urol. 40, 33.

Lonsdale, K., Sutor, D. J. \& Wooley, S. E. (1968b). Br.J. Urol. 40, 402.

Sutor, D. J. (1969). Br.J. Urol.41, 171.

Sutor, D. J. (1970). Br. J. Urol. 42, 389.

Sutor, D. J. \& Wooley, S. E. (1969). Br. J. Urol. 41, 397.

Sutor, D. J. \& Wooley, S. E. (1970a). Br.J. Urol. 42, 296.

Sutor, D. J. \& Wooley, S. E. (1970b). Br.J. Urol. 42, 302.

Thomas, W. C., jun. (1969). In Renal Stone Research Symposium, Chapter 15, p. 141. Ed. by Hodgkinson, A. \& Nordin, B. E. C. London: J. and A. Churchill Ltd.

\section{Primary Hyperoxaluria}

By R. W. E. WATts. (Medical Research Council Clinical Research Centre, Watford Road, Harrow HA1 3UJ, U.K.)

Patients with primary hyperoxaluria present with calcium oxalate urinary stones and are found to have an abnormally high urinary excretion of oxalate. The stone formation usually begins in childhood and the victims die in early life because their kidneys are destroyed inexorably by recurrent urolithiasis and nephrocalcinosis. However, stone formation begins later in a few cases. Disseminated extra-renal deposits of calcium oxalate ('oxalosis') are found at autopsy; these are particularly prominent in the myocardium, muscular parts of the arterial walls and in the rete testis. Only a minority of patients with calcium oxalate urolithiasis have primary hyperoxaluria, but its presence should be sought in all patients who have a calcium oxalate stone. The rate (mg/24h) at which normal subjects 
excrete oxalate in the urine increases during childhood and reaches adult values by the age of 14 years; however, this age difference disappears if the results are related to a standard body surface area $(\mathrm{mg} / 24 \mathrm{~h}$ per $1.73 \mathrm{~m}^{2}$ ) (Gibbs \& Watts, 1969). Theliterature on the determination of oxalate in biological materials was fully reviewed by Hodgkinson (1970). Almost all of the published pedigrees of families in which cases of primary hyperoxaluria have occurred are compatible with the disease being due to a recessively inherited abnormality, although there have been occasional reports of apparently dominant inheritance of the condition (Wyngaarden \& Elder, 1966).

Williams \& Smith (1968) classify cases of primary hyperoxaluria into Types I and II respectively. Type I cases have hyperglycollic aciduria as well as hyperoxaluria, and also excrete increased amounts of glyoxylate in their urine (Hockaday, Frederick, Clayton \& Smith, 1965). The urinary excretion of $\mathbf{L}(+)$-glyceric acid as well as that of oxalate is increased in cases of Type II primary hyperoxaluria, whereas the excretion of glycollate is normal (Williams \& Smith, 1968).

Several differently designed studies with isotopically labelled precursors in vivo (Crawhall, Scowen \& Watts, 1959; Elder \& Wyngaarden, 1960; Frederick, Rabkin, Richie \& Smith, 1963; Hockaday, Clayton \& Smith, 1965; Dean, Watts \& Westwick, 1968) indicated that the carbon skeletons of glycine, glyoxylate and glycollate were incorporated into the urinary oxalate in vivo. These studies suggested that the biochemical lesion in primary hyperoxaluria was a failure to metabolize glyoxylate normally, the accumulated glyoxylate being oxidized to oxalate and excreted in the urine. Crawhall \& Watts (1962a) demonstrated a synergistic decarboxylation of glyoxylate and 2-oxoglutarate in mitochondria from both rat and human liver. This reaction was subsequently studied further and the enzyme system concerned, 2-oxoglutarate-glyoxylate carboligase, purified by Koch \& Stokstad (1966) and by Stewart \& Quayle (1967).

Koch, Stokstad, Williams \& Smith (1967) measured the 2-oxoglutarate-glyoxylate carboligase activity of both the mitochondrial and 'soluble' fractions of liver, kidney and spleen and found that the activity of the soluble fraction, but not of the mitochondrial enzyme, was decreased in Type I primary-hyperoxaluria patients in all three tissues. Crawhall \& Watts (1962b) had reported that hyperoxaluric and normal subjects' liver mitochondria metabolized $\left[1 .{ }^{14} \mathrm{C}\right]$ glyoxylate to ${ }^{14} \mathrm{CO}_{2}$, $\left[{ }^{14} \mathrm{C}\right]$ glycine and $\left[{ }^{14} \mathrm{C}\right]$ oxalate equally effectively. Dean, Watts \& Westwick (1967) found that glycine formation, as well as ${ }^{14} \mathrm{CO}_{2}$ production, from [1-14 $\mathrm{C}$ ]glyoxylate was decreased in whole homogenates of kidney tissue from patients with primary hyperoxaluria. Both of the latter studies were made before the differentiation of Type I from Type II primary hyperoxaluria was appreciated.

The metabolic lesion in Type II primary hyperoxaluria was identified as $\mathrm{D}$-glycerate dehydrogenase (D-glycerate-NAD oxidoreductase, EC 1.1.1.29) deficiency by Williams \& Smith (1968), who demonstrated the enzyme deficiency in the patients' leucocytes. These authors suggest that, in the absence of this enzyme, hydroxypyruvate is reduced to L-glycerate by L-lactate-NAD oxidoreductase (EC 1.1.1.27), the L-glycerate being excreted in the urine. The cause of the hyperoxaluria in these cases has not been fully elucidated, but Williams \& Smith (1968) suggest that Dglycerate dehydrogenase normally reduces glyoxylate to glycollate as well as reducing hydroxypyruvate to $\mathrm{D}(-)$-glycerate, so that in its absence glyoxylate tends to accumulate and is oxidized to oxalate by other enzymes.

Experimentally induced pyridoxine deficiency increases the urinary excretion of oxalate in animals (Gershoff, Faragella, Nelson \& Andrus, 1959) as well as in man (Faber, Feitler, Bleiler, Ohlsen \& Hodges, 1963). Large oral doses of pyridoxine decrease the urinary oxalate excretion in some cases of primary hyperoxaluria, but the reason for this variability between different patients remains to be elucidated. These differences have not been correlated with the classification of the patients into Types I and II, and the pattern of tryptophanmetabolite excretion after an L-tryptophan load is different from that occurring in abnormalities of pyridoxine metabolism (Gibbs \& Watts, 1970).

It would be theoretically attractive to treat primary hyperoxaluria by inhibiting oxalate biosynthesis, and in particular the last step on the metabolic pathway, namely the oxidation of glyoxylate to oxalate. Previous attempts to do this, by giving drugs that inhibit xanthino-oxygen oxidoreductase (EC 1.2.3.2) and aldehyde-NAD oxidoreductase (EC 1.2.1.3), did not decrease the urinary oxalate excretion in studies which were carried out for a sufficient length of time to allow for the spontaneous fluctuations in the daily rate of urinary oxalate excretion, which occur in the disease (Gibbs \& Watts, 1967, 1968). Further work in this area is in progress.

Crawhall, J. C., Scowen, E. F., \& Watts, R. W. E. (1959). Lancet, ii, 806.

Crawhall, J. C. \& Watts, R. W. E. (1962a). Biochem. J. 85, 163.

Crawhall, J. C. \& Watts, R. W. E. (1962b). Clin. Sci. 23, 163.

Dean, B. M., Watts, R. W. E. \& Westwick, W. J. (1967). Biochem.J. 105, 701. 
Dean, B. M., Watts, R. W. E. \& Westwick, W. J. (1968). Clin. Sci. 35, 325.

Elder, T. D. \& Wyngaarden, J. B. (1960). J. clin. Invest. 39, 1337.

Faber, S. R., Feitler, W. W., Bleiler, R. E., Ohlsen, M. A., \& Hodges, R. E. (1963). Am. J. clin. Nutr. 12, 406.

Frederick, E. W., Rabkin, M. T., Richie, R. H. \& Smith, L. H. (1963). New Engl. J. Med. 269, 822.

Gershoff, S. N. Faragella, F. F., Nelson, D. A. \& Andrus, S. B. (1959). Am. J. Med. 27, 72.

Gibbs, D. A. \& Watts, R. W. E. (1967). Archs Dis. Childh. 42, 505.

Gibbs, D. A. \& Watts, R. W. E. (1968). Archs Dis. Childh. $43,313$.

Gibbs, D. A. \& Watts, R. W. E. (1969). J. Lab. clin. Med. 73, 901.

Gibbs, D. A. \& Watts, R. W. E. (1970). Clin. Sci. 38, 277.

Hockaday, T. D. R., Clayton, J. E. \& Smith, L. H. (1965). Archs Dis. Childh. 40, 485.

Hockaday, T. D. R., Frederick, E. W., Clayton J. E., \& Smith, L. H. (1965). J. Lab. clin. Med. 65, 677.

Hodgkinson, A. (1970). Clin. Chem. 16, 547.

Koch, J. \& Stokstad, E. L. R. (1966). Biochem. biophys. Res. Commun. 23, 585.

Koch, J., Stokstad, E. L. R., Williams, H. E. \& Smith, L. H. (1967). Proc. natn. Acad. Sci. U.S.A. 57, 1123.

Stewart, P. R. \& Quayle, J. R. (1967). Biochem. J. 102, 885.

Williams, H. E. \& Smith, L. H. (1968). New Engl.J. Med. 278, 233.

Wyngaarden, J. B. \& Elder, T. D. (1966). In The Metabolic Basis of Inherited Disease, p. 189. Ed. by Stanbury, J. B., Wyngaarden, J. B. \& Fredrickson, D. S. New York: McGraw-Hill.

\section{The Metabolic Basis of Uric Acid Stone For-} mation

By O. M. Wrong. (Department of Medicine, University of Dundee, Dundee, U.K.)

The two main factors known to be associated with uric acid calculi are: (1) a high urinary concentration of uric acid/biurate, caused either by an increased urinary excretion or a decreased urinary volume; (2) a urine persistently in the more acid range under $\mathrm{pH} 6.0$ (urine $\mathrm{pH}$ normally shows fluctuation between 4.6 and 8.0). The $p K_{1}$ of uric acid is in the region of 5.6. Uric acid and biurate both tend to form supersaturated solutions in urine, but the solubility of biurate is about 17 times that of uric acid, and precipitation is therefore more likely to occur from urines which are more acid, especially under pH 5.6.

In Western Europe, U.S.A. and Israel themajority of adult patients with uric acid calculi show no increase in uric acid/biurate, but a highly significant decrease in urine $\mathrm{pH}$. The cause of this more-acid urine is still uncertain, but there are several explanations (which will be reviewed) and the mechanism may not be the same in all patients.

Alkalinization of the urine, with oral sodium bicarbonate or citrate, is the most important principle in the prevention of further attacks of uric acid calculi, and is very effective.

\section{Amino Acid Metabolism in Gystinuria}

By M. D. Mrune. (Department of Medicine, Westminster Medical School, 17 Page Street, London S.W.1, U.K.)

Cystine calculi account for about $1 \%$ of urinary stones in adult life, but a relatively higher proportion in childhood. Cystinuria is an autosomal recessive hereditary disease, the frequency of homozygotes in the general population being approx. 1 in 20000 . The maximum solubility of cystine in urine of $\mathrm{pH} 4.5-7.0$ is about $300 \mathrm{mg} / \mathrm{l}$. As adult cystinuric patients usually excrete 600$1300 \mathrm{mg}$ of cystine daily, the amino acid often crystallizes and may form calculi. The peak age of clinical presentation is in the third decade, but about $8 \%$ of patients have symptoms and signs of calculi before the age of 10 , and in a few patients calculi are first formed in extreme old age. The disease considerably decreases life expectancy, the mean age of death in a recent series being 52 in males and 64 in females. In addition, cystinuria causes considerable discomfort and disability from renal colic, chronic pyelonephritis and, eventually, chronic renal failure. Cystinuric patients often have to submit to repeated surgical operations for removal of calculi. Factors increasing the liability to stone formation are oliguria, a highly acidic urine, a high protein diet, and urinary obstruction and infection. Many of these factors are controllable, and therapy with a high-fluid regime undoubtedly lessens the tendency to form renal stones. Calculi, however, are especially liable to form during sleep, when the urine is of maximum acidity and osmolality. Effective fluid therapy must, therefore, inevitably interfere with sleep, as it is of particular importance to preserve a dilute and copious urine flow throughout the whole 24 hours. In unco-operative patients in whom there is stone formation despite attempts at a high-fluid regime, penicillamine therapy is necessary to decrease urinary cystine output. The main urinary sulphur-containing amino acid during effective penicillamine treatment is the mixed disulphide of penicillamine and cysteine. Because of the asymmetry of the molecule, this compound is much more soluble than is cystine.

It is now generally agreed that the basic abnormality of the disease is an impaired transport capacity for cystine, lysine, arginine and ornithine by the proximal renal tubular cells and by the intestinal mucosa. Were it not for the relative insolubility of cystine in urine, cystinuria would be a completely harmless metabolic anomaly. The 